\title{
BMJ Open Temporal variation and geospatial clustering of dengue in Delhi, India 2015-2018
}

\author{
Poornima Suryanath Singh, ${ }^{1}$ Himanshu K Chaturvedi (i) ${ }^{2}$
}

To cite: Singh PS, Chaturvedi HK. Temporal variation and geospatial clustering of dengue in Delhi, India 2015-2018. BMJ Open 2021;11:e043848. doi:10.1136/ bmjopen-2020-043848

- Prepublication history for this paper is available online. To view these files, please visit the journal online (http://dx.doi org/10.1136/bmjopen-2020043848).

Received 17 August 2020 Revised 07 December 2020 Accepted 25 January 2021

Check for updates

(c) Author(s) (or their employer(s)) 2021. Re-use permitted under CC BY-NC. No commercial re-use. See rights and permissions. Published by BMJ.

${ }^{1}$ University School of Medicine \& Paramedical Health Sciences, Guru Gobind Singh Indraprastha University, New Delhi, India ${ }^{2}$ ICMR-National Institute of Medical Statistics, New Delhi, India

Correspondence to Dr Himanshu K Chaturvedi, ICMR-National Institute of Medical Statistics, New Delhi, Delhi, India;

chaturvedi_icmr@yahoo.com

\section{ABSTRACT}

Objectives The study was focused on geographical mapping of dengue cases and also to identify the hotspots or high-risk areas of dengue in Delhi.

Design A retrospective spatial-temporal (ecological) study. Descriptive analysis was used to know the distribution of dengue cases by age, sex, seasons and districts of Delhi. The spatiotemporal analysis was performed using inverse distance weighting and Getis-Ord Gi* statistic to know the geographical distribution and identify the hotspot areas.

Settings All the confirmed and diagnosed dengue cases (IgM +veor NS1 Antigen +ve ELISA) recorded by the Municipal Corporation of Delhi for the last 4 years (2015-2018) were collected with their local address. The location of all the dengue cases was geocoded using their address to prepare the spatiotemporal dengue database.

Participants Record of all the dengue cases (4179) reported for treatment in the hospitals during the past 4 years were extracted and included in the study. Data were not collected directly from dengue patients.

Results Seasonal occurrence of dengue cases (4179) shows that the cases start emerging in July, peaked in SeptemberOctober and declined in December. The proportions of dengue cases were recorded high among the males $57.3 \%$ compared with females $42.6 \%$, and differences were also recorded in all the age groups with more cases in age groups $<15$ and $16-30$ years. Mapping of the cases reflects the spatial heterogeneity in the geographical distribution. The geomapping of cases indicates the presence of a significantly high number of cases in West, Southwest, South and Southeast districts of Delhi. High-risk areas or hotspots were also identified in this region. Conclusion Dengue occurrence shows significant association with age, sex and seasons. The spatial analysis identified the high-risk areas, which can aid health administrators to take necessary action for prevention and better disease management.

\section{INTRODUCTION}

Dengue is a tropical and subtropical disease which is primarily transmitted to humans by the female Aedes mosquito species Aedes aegypti and Aedes albopictus. Dengue is caused by a virus of the Flaviviridae family (DEN 1-4) and infection with DENV may lead to varying degrees of pathological conditions which may turn fatal. ${ }^{1}$ Dengue is endemic in more than 100 countries in Asia (including Southeast Asia), the Pacific (particularly Western Pacific), Eastern

\section{Strengths and limitations of this study}

- The study collected all the clinically confirmed dengue cases recorded in the last 4 years in Delhi and identified their geographical locations.

- The proposed research is geographical mapping and the spatial analysis of dengue cases to identify the geographical clustering and local hotspots in Delhi.

- Investigation and identified hotspots could be main outcome for targeted intervention to control vectors and dengue transmission in the identified high incidence dengue areas.

- The environmental and socioeconomic factors could be the reason of high and low transmission of disease, but it was not exploered in this study.

- Spatiotemporal analysis may not be useful if dengue cases are distributed randomly in the geographical areas.

Mediterranean, the USA, Africa and the Caribbean. ${ }^{2}$ Currently, 2.5 billion people are living in high-risk areas of dengue and about 100 million cases reported every year. ${ }^{34}$ According to $\mathrm{WHO}$, the 500000 cases progress to dengue haemorrhagic fever (DHF) with approximately 22000 deaths. ${ }^{5}$ The endemic areas of dengue fever is rapidly spreading and becoming a global burden affecting over half the world's population. ${ }^{6}$

In India, the first outbreak of dengue fever was reported during 1963 in Kolkata, and subsequently, the dengue fever epidemic occurred in the eastern coast of India during 1963-1964, which was virologically proved..$^{7-9}$ The dengue infection expanded northwards to Delhi in 1967 and later, the entire country had epidemics followed by endemic or hyperendemic prevalence. After 1967, the major outbreaks of dengue in Delhi were reported in 1996, and thereafter, it was frequently reported in 2003, 2006, 2010 and 2013, 2015. ${ }^{10-12}$ Globalisation, urbanisation, poor disease control activities are some of the important reasons for the increase of dengue ${ }^{13}$ in Delhi.

Various studies indicate that dengue continues to be an important public health problem in India, as evidenced by the high proportion of 
dengue positivity, severity and case fatality. ${ }^{14}$ The increasing problem of dengue necessitates reforming the control strategies and taking a timely intervention to prevent future epidemics. In the present scenario, disease control has been focused on measures to control the mosquito vectors, but it has had limited effectiveness in preventing dengue fever transmission. ${ }^{15}$ Currently, geographical information system (GIS) techniques have been used widely to study issues of public health. Detection of disease by integrating spatial patterns, identifying unusual aggregations (hotspots) of epidemiological events and the forecasting of high-risk areas of disease transmission is possible on the GIS platform. ${ }^{16}$ Several studies related to DHF have been conducted by some researchers but it was not focused on the spread/spatial distribution of dengue in the region. ${ }^{8-11}$ Thus, an analysis of the registered dengue cases and an identification of risk patterns become necessary.

The spatial distribution of dengue fever in Delhi is a complex process and remains unexplored. The present study aims to know the temporal variation and identify the geospatial clustering and hotspots of dengue cases using the GIS Spatial-temporal analysis. The identification of the geographical location of hotspots will be used to avert the spread of dengue disease by ensuring timely preventive and control measures and also to reduce morbidity and mortality.

\section{METHODS}

\section{Study area}

Delhi, the National Capital Territory of Delhi (figure 1), is one of the largest city and densely populated state of the country covering an area of $1484 \mathrm{~km}^{2}$, and population 16787941 with density 11320 persons per $\mathrm{km}^{2}$ (Census 2011). Delhi is divided into eleven districts(figure 1) which varies widely by areas $\left(21-443 \mathrm{~km}^{2}\right)$, population (582320-3656539 persons) and density (4047-27730 persons $/ \mathrm{km}^{2}$ ). Delhi experiences tropical steppe type of

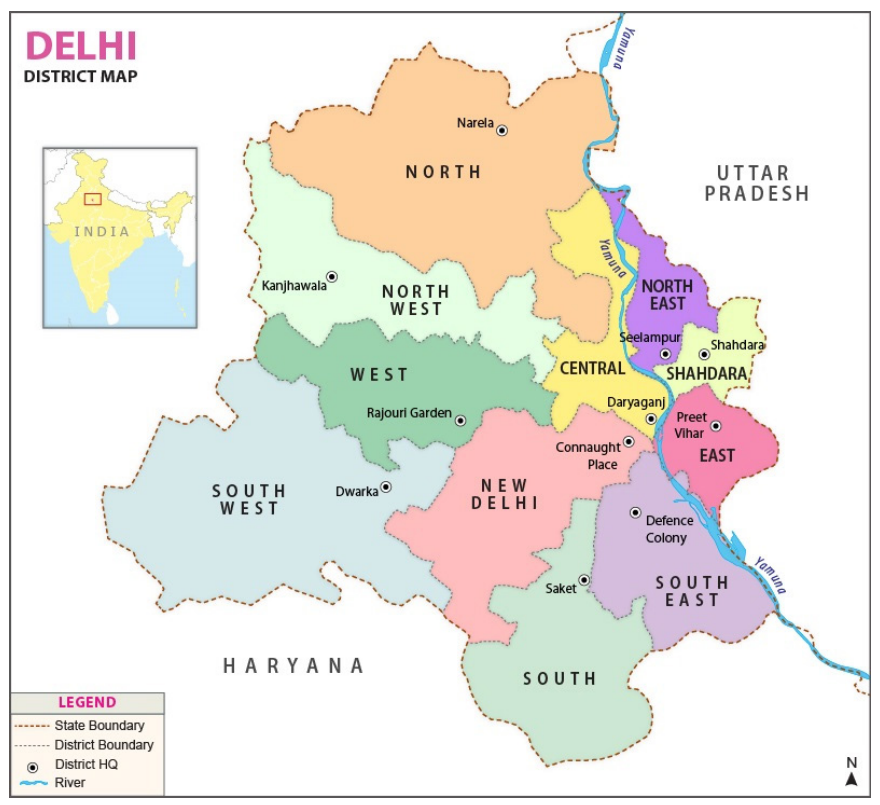

Figure 1 Geographical map of Delhi, India. climate and seasons are marked with extreme temperatures ranging from $2^{\circ} \mathrm{C}$ to $47^{\circ} \mathrm{C}$, average rainfalls of $886 \mathrm{~mm}$ per annum. Monsoon period is from July to midSeptember when the climate remains wet and humid. The main reasons for selecting Delhi as the study site, because it has reported a large number of dengue cases every year (2015-2018) and become hyperendemic. ${ }^{17}{ }^{18}$ Also, Delhi has the highest population density and the city has recorded high growth in the population during the last two decades, which was mainly due to high migration and increasing urbanisation. Both population density and rapid urbanisation are critical for dengue transmission in Delhi.

\section{Source of data collection}

As dengue is a notifiable disease, all laboratory diagnosed positive cases (IgM +ve or NS1 Antigen +ve ELISA) were reported and recorded with the name of the hospital, location of the case (name of colony/street, subdivision and districts) with the date of notification of confirmed dengue cases by the health administration of Delhi. More than $80 \%$ of cases were admitted in the hospital as inpatients and rest of them taken treatment as outpatients, but all are diagnosed and received treatment from the hospital. Computerised data of dengue cases were obtained from January 2015 to December 2018 (4 years) from the Municipal Corporation of Delhi, a government administration maintaining the data. The seroepidemiological data provide information of locally acquired dengue confirmed cases with age (ranging from 0 to 92 years), sex (male/female), locality of residence (smaller area of subdivision of districts identified form the location information of each dengue cases), the hospital name (government hospital/private hospital), date of admission (recorded for more than $80 \%$ of cases), date of notification of all cases, including IgM +ve/NS1 antigen +ve by ELISA as confirmation of Dengue. The data required for the study were extracted from the main database and all clinically confirmed positive cases with other information were included in the analysis.

All the dengue cases included in the study were recorded as clinically confirmed as the non-structural glycoprotein-1 was tested positive in the ELISA or serology DENV IgM and IgG titres were determined positive by ELISA. This is also according to the WHO guideline of confirmed dengue cases.

\section{Data analysis}

Descriptive analysis was used to know the epidemiological distribution of dengue cases by age, sex and seasonal pattern (monthly), and district-wise distribution of cases in different years. The $\chi^{2}$ test was used to know the association of age, sex, seasons and districts with the proportion of dengue cases. The location information comprises the name of the district, within the district name of subdivision, and also within subdivision the name of colony/ street/sector (smaller are of subdivision) which was used to prepare geocode for location of dengue cases. 
However, it is possible to have the same geocode for more than one cases if more number of cases recorded from the same location. Also, there may be some location/area where no case was recorded, but that has been taken care of by the GIS software in the analysis. All the point locations of dengue cases were referenced to their location for geospatial analysis using the geocoded (latitude and longitude coordinates obtained for each case) information and Google maps (www.google.co.in/maps). The point shapefile was prepared using ArcGIS (www.esri. com). The IBM SPSS V.23 was used for descriptive analysis of data.

The spatial and temporal analysis was performed using the inverse distance weighted (IDW) interpolation using ArcGIS. The power was used two for IDW and search index was variable (options used for analysis). The IDW assumes that each input point has a local influence that decreases with distance, and weights the points closer to the processing points more than those farther away. ${ }^{19}$ Spatial autocorrelation analysis was also used to test the spatial distribution of cases over geographical space (using aggregated cases in each district of Delhi). The hotspot analysis or GetisOrd Gi*statistic (a spatial statistics tool) in ArcGIS was used to identify the significant clusters with a high frequency of dengue cases. According to the spread of point location of cases, the distance band or threshold value was taken as default by the software. The Getis-Ord Gi* used to test for autocorrelation for each year and indicate significant hotspots $(\mathrm{p}<0.05) .{ }^{20-22}$

\section{Patients and public involvement}

The patients and the public were not involved in the design or planning of the study.

\section{RESULTS}

Of 4719 total confirmed dengue cases, the highest number of cases (3189) was recorded in 2015, but it was declined in 2016 (545 cases), again slightly increased in 2017 (706 cases), and there was a sharp decline in 2018 (279 cases). Dengue cases according to sex, age, seasons and districts of Delhi are presented in table 1. Dengue cases in males were comparatively higher than females in all the 4 years. It was $60.0 \%$ males and $40.0 \%$ females in 2015 ; $52.8 \%$ males and $47.2 \%$ females in 2016 ; $58.5 \%$ males and $41.5 \%$ females in 2017; and $58.1 \%$ males and

Table 1 Annual distribution of dengue cases by age, sex, season and districts in Delhi (2015-2018), India

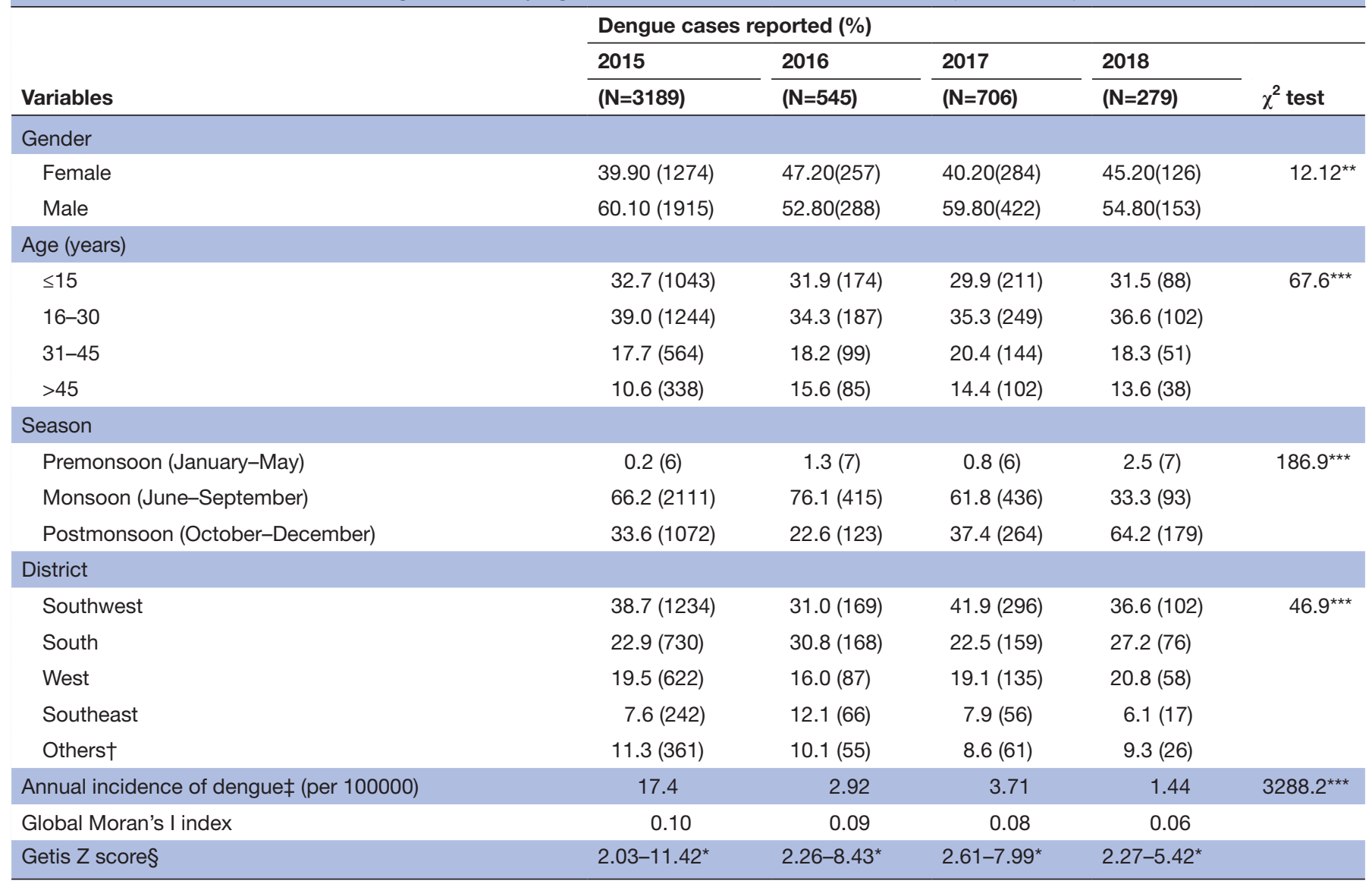

${ }^{*} \mathrm{P}<0.05,{ }^{* *} \mathrm{p}<0.01,{ }^{* * *} \mathrm{p}<0.001$.

†Includes the remaining seven districts (New Delhi, East, North, Northeast, Northwest, Shadra and Central Delhi).

fUsed projected population of Delhi.

$\S$ All identified significant hot spots $(p<0.05)$. 


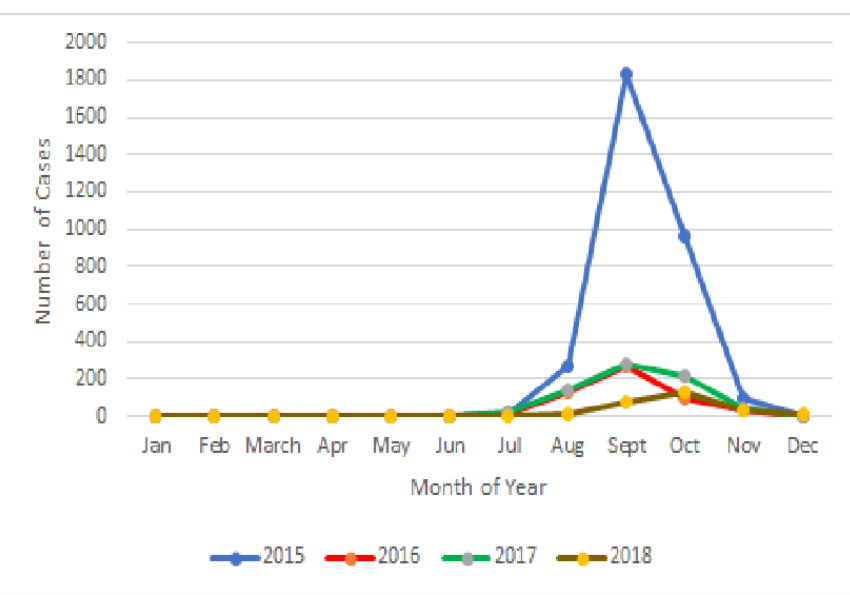

Figure 2 Monthly distribution of dengue cases in Delhi for four years (2015-2018).

41.9\% females in 2018. The occurrence of dengue cases by sex and years was significantly associated $(p<0.001)$. Though dengue cases were quite prevalent in all age groups, it was comparatively high in the age groups of $\leq 15$ and 16-30 years compared with other age groups. The pattern of cases by age groups was similar in all the 4 years. Association of occurrence of dengue cases by age and years was recorded significant $(\mathrm{p}<0.001)$.

The seasonal pattern of disease occurrence indicates that the dengue cases started emerging mainly in JuneJuly during the monsoon season increased gradually to a high peak in September-October during the postmonsoon period and thereafter, declined and reached a lowest in November-December during early winter (figure 2). Cases reported in September was high in 2015 and 2016, but it was shifted to October in 2017 and 2018. The association of occurrence cases with season and years was also significant $(\mathrm{p}<0.001)$. High annual incidence of dengue(per 100000) was recorded (17.4) in 2015, but it was declining to 1.44 in 2018 and $\chi^{2}$ (trend) was significant $(p<0.001)$. The four districts of Delhi recorded about $90 \%$ of dengue cases viz Southwest, South, West and Southeast Delhi; and remaining seven districts contributed only $10 \%$ of cases in each year, respectively (table 1 ).

\section{Spatial analysis}

The spatial analysis of dengue cases presents the geographical map of cases in Delhi according to their location for each year (figure 3 ). The dengue cases were mainly concentrated in Southwest, South, West and Southeast districts of Delhi. However, the intensity of cases in those districts was high in 2015, but it was low in the year 20162018. The spatial autocorrelation measured by Moran's I (global) was positive for all the 4 years as presented in table 1, but it was not high (0.098 for 2015, 0.089 for 2016, 0.080 for 2017 and 0.059 for 2018). Geospatial maps with the intensity of disease were generated by using the IDW and presented in figure 4 . The high and low concentration of weighted cases depicted in a choropleth map. The presence of a high concentration of cases in the region

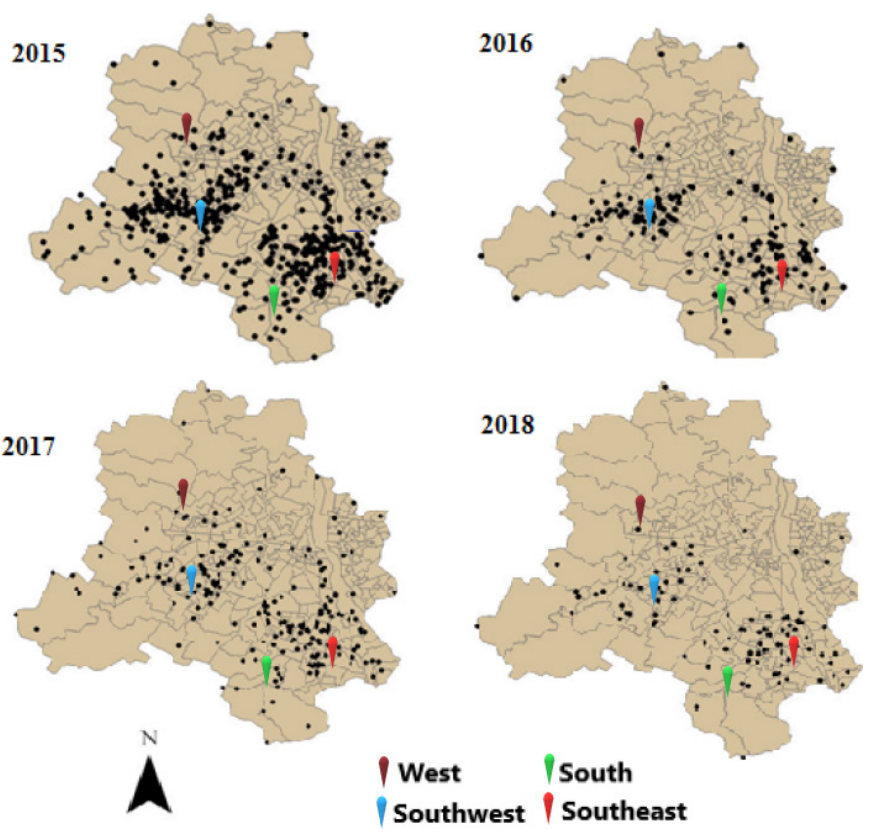

Figure 3 Spatial distribution and geographical location of concerted dengue cases in Delhi (2015-2018).

of Southwest and West districts of Delhi was revealed in map with differences in coverage areas highlighted in red and yellow colour. Cases in some region of Southwest and East districts of Delhi were also observed in 2015, 2016 and 2017.

\section{Hotspot analysis-Getis}

The geographical location of the hotspots of dengue cases was identified by Getis-Ord Gi and presented on the map of Delhi separately for each year (figure 5). Hotspot analysis indicates that 14 hotspots with $95 \%$ CI (5 in Southwest, 5 in West and 4 in Southeast district)

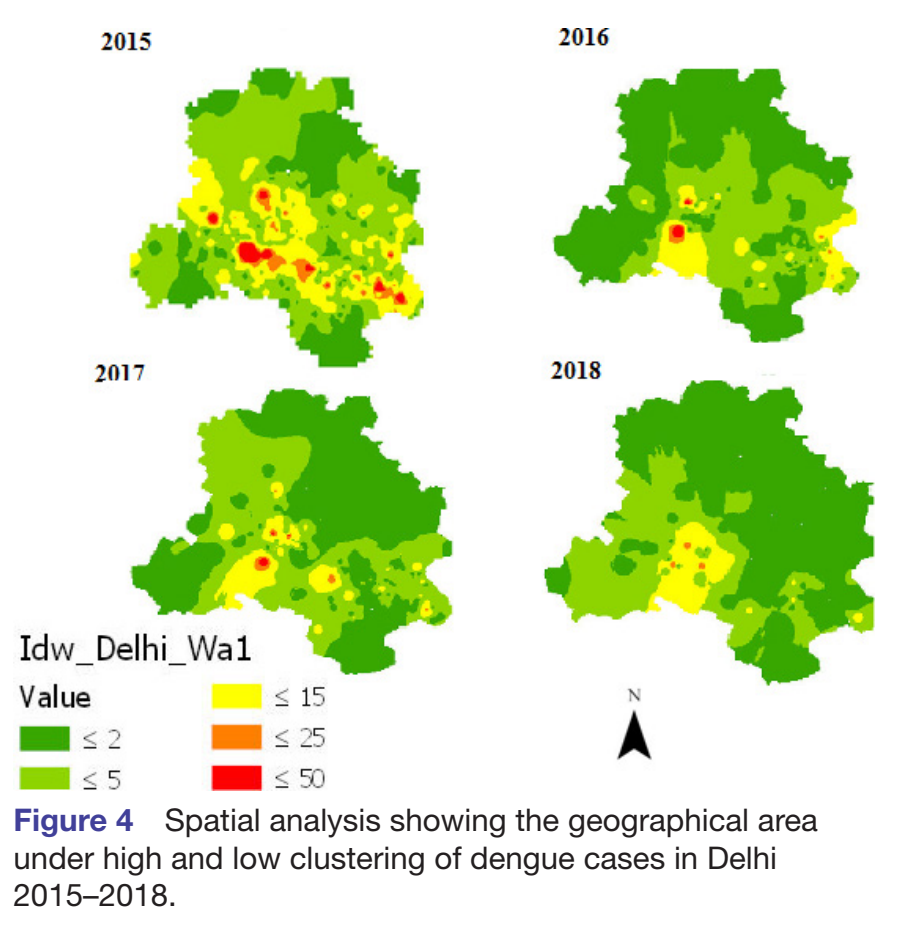




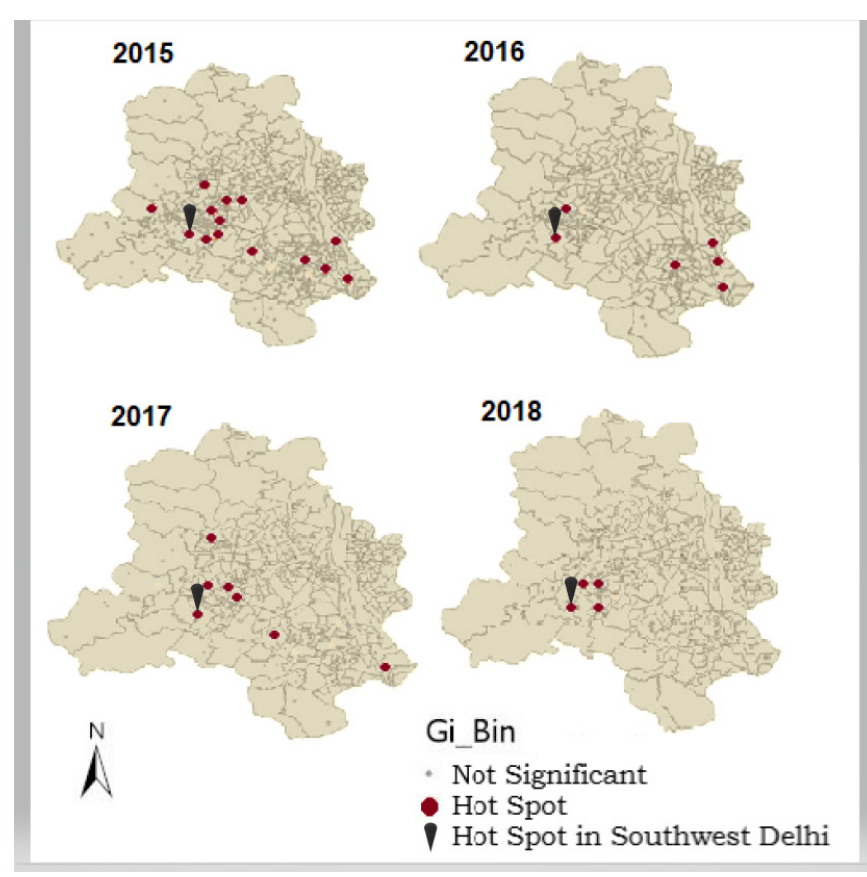

Figure 5 Geties significant hotspots areas of dengue in Delhi 2015-2018.

were identified for 2015; six hotspots with 95\% CI (one in West, one in Southwest and four in Southeast district) in 2016; eight hotspots with 95\% CI (one in Northwest, two in Southwest, three in West, one each in South and Southeast districts) in 2017; and four hotspots (two in Southwest and two in West) in 2018 in Delhi. These identified hotspot areas are the smaller region of the district which can be mapped as an urban ward or urban village or slum areas.

\section{DISCUSSION}

Dengue cases recorded in the last 4years (2015-2018) indicates a declining trend which was possibly due to increasing health awareness among the people and systematic control measures taken by the government. But it was reported every year from different parts of Delhi and remains as a major public health problem in Delhi. The analysis revealed the gender association with occurrence dengue cases. Male and female ratio of dengue cases in India was reported 1.9:1, 1:0.57 and 2.5:1 in different studies, ${ }^{23-25}$ which was comparable to our findings (1.4:1). The high proportion of cases recorded among males compared with females was also reported from Saudi Arabia, Cambodia, Malaysia, Sri Lanka, Singapore, the Philippines including India which was possibly due to more exposure of outdoor work by male's increases the risk of mosquitoes bites. ${ }^{1726-29}$

The association of age with the occurrence of dengue cases was significant and more cases recorded in the younger ( $<15$ years) and adult age . Study in Gujarat also reported that the proportion of cases among children up to age 14 was high $(26.2 \%)$ compared with age group 15-44years $(17.3 \%){ }^{30}$ The reason behind the high incidence in younger age was possibly due to the cocirculation of multiple serotypes of dengue increases disease susceptibility. ${ }^{31}$ However, more cases in the adult were possibly due to more exposure infection during outdoor working activities. $^{26}$

The occurrence of dengue cases was associated with seasons which were also reported by other studies from Gujarat and Delhi. ${ }^{1730}$ Increasing number of cases during the postmonsoon and peak in September-October was also reported by others. ${ }^{1732}$ This was mainly due to more breeding sites in the stagnant water after the monsoon, which, in turn, leads to an increase in the number of mosquitoes hatching. However, high rainfall during monsoon has also a decreasing effect on mosquito density due to washout of breeding sites. ${ }^{33}$

The spatial and temporal analysis of dengue cases in Delhi shows the spatial diffusion patterns and significant variation in the spatial distribution enabling identification of hotspots dengue areas. The areas under the hotspots and its number have been reduced every year from 2015 to 2018. But the occurrence of disease confined to the same geographical areas in the southern region of Delhi with some common hotspots in all the 4 years. A study conducted in 2017 showed the occurrence of dengue cases simultaneously in the same district or adjacent districts in India. ${ }^{34}$ The presence of dengue cases was mainly confined to four districts of Delhi, namely South, Southwest, West and Southeast in all 4 years with varying disease intensity as reported by others. ${ }^{18}$ Spatial distribution of dengue cases with the significant pattern of clustering was inevitable as the human population generally live in spatial clusters rather than randomly distributed in space. ${ }^{34}$

Overall, it is evident that still there are some hotspots which remain as high-risk areas of dengue in Delhi. Identification of hotspots and high-risk areas are useful for targeting the intervention to control of vectorborne disease such as dengue ${ }^{1635}$ by incrimination of the mosquito vectors. Such identification has operational implication to detect and respond with a proper surveillance system ${ }^{18}$ for better control of dengue.

The findings of the study have some limitation as it is based on the analysis of reported data of dengue cases provided by public and private hospitals of Delhi. Although dengue is a notifiable disease and became mandatory to record all the cases reported to the hospitals, under-reporting of dengue cases may be possible which may have some effect on the overall outcome of the study. But the area identified as hotspots may not be changed.

As no medicine or any vaccine is available for the treatment of dengue fever (WHO 2010), the reductions of vector breeding habitats are the best approach to control the disease epidemics. The spatial-temporal analysis of dengue cases useful in identifying the hotspots in Delhi which can be mapped geographically as highrisk areas and timely action may be taken for prevention and control of dengue. The findings of the spatial 
analysis are useful for targeted intervention to control the dengue in hotspots areas and also to combat the spread of dengue. This can be achieved by sharing the findings and discussing its advantages with the local health administration and dengue control team of Delhi.

Acknowledgements The authors are thankful to all the experts of School Research Committee (SRC), Guru Gobind Singh Indraprastha University, New Delhi and Ethics Committee of ICMR-National Institute of Medical Statistics, New Delhi for their valuable suggestion and approval of the study. We are also thankful to Dr. Lallan Ram, Additional director Municipal Corporation of Delhi and his office staff for necessary help in collecting the dengue records.

Contributors PSS and $\mathrm{HC}$ conceived and contributed to study design. PSS performed the data collection, analysis and writing the manuscript. HC provided necessary help in data collection, analysis and interpretation of results, and final writing of the manuscript. The authors read and approved the final manuscript.

Funding The authors have not declared a specific grant for this research from any funding agency in the public, commercial or not-for-profit sectors.

Map disclaimer The depiction of boundaries on this map does not imply the expression of any opinion whatsoever on the part of BMJ (or any member of its group) concerning the legal status of any country, territory, jurisdiction or area or of its authorities. This map is provided without any warranty of any kind, either express or implied.

\section{Competing interests None declared.}

Patient and public involvement Patients and/or the public were not involved in the design, or conduct, or reporting, or dissemination plans of this research.

Patient consent for publication Not required.

Ethics approval This study was undertaken after getting approval of the study proposal from the School Research Committee of the university and Ethics Committee of the Institute constituted by Indian Council of Medical Research, New Delhi.

Provenance and peer review Not commissioned; externally peer reviewed.

Data availability statement Data may be obtained from a third party and are not publicly available. Data collected in this study are available only for the research purpose and it is available with the Health Administration, Delhi.

Open access This is an open access article distributed in accordance with the Creative Commons Attribution Non Commercial (CC BY-NC 4.0) license, which permits others to distribute, remix, adapt, build upon this work non-commercially, and license their derivative works on different terms, provided the original work is properly cited, appropriate credit is given, any changes made indicated, and the use is non-commercial. See: http://creativecommons.org/licenses/by-nc/4.0/.

\section{ORCID iD}

Himanshu K Chaturvedi http://orcid.org/0000-0001-9395-8522

\section{REFERENCES}

1 Chen R, Vasilakis N. Dengue-quo tu et quo vadis? Viruses 2011;3:1562-608.

2 Ganguly KS, Ganguly KS, Chattopadhyay AK, et al. Spatial clustering of dengue fever: a baseline study in the city of Kolkata. Int $J$ Health Med Sci 2018;4:170-87.

3 World Health Organization. Dengue and dengue haemorrhagic fever. fact sheet No. 117. Geneva: World Health Organisation, 2008. http:// wwwwho.int/mediacentre/factsheets/fs117/en/

4 Gibbons RV, Vaughn DW. Dengue: an escalating problem. BMJ 2002;324:1563-6.

5 World Health Organization. Impact of dengue [online], 2015. Available: http://www.who.int/csr/disease/dengue/impact/en/

6 Messina JP, Brady OJ, Golding N, et al. The current and future global distribution and population at risk of dengue. Nat Microbiol 2019;4:1508-15.

7 Carey DE, Rodrigues FM, Reuben R, et al. Studies on dengue in Vellore, South India. Am J Trop Med Hyg 1966;15:580-7.
8 Sarkar JK, Chatterjee SN, Chakravarty SK. Haemorrhagic fever in Calcutta: some epidemiological observations. Indian J Med Res 1964;52:651-9.

9 Chatterjee SN, Chakravarti SK, Mitra AC, et al. Virological investigation of cases with neurological complications during the outbreak of haemorrhagic fever in Calcutta. $J$ Indian Med Assoc 1965;45:314-6.

10 Gupta N, Srivastava S, Jain A, et al. Dengue in India. Indian J Med Res 2012;136:373-90.

11 Savargaonkar D, Sinha S, Srivastava B, et al. An epidemiological study of dengue and its coinfections in Delhi. Int $J$ Infect Dis 2018;74:41-6.

12 Annual reports (vector borne diseases), MIS cell, South Delhi municipal Corporation.

13 Gubler DJ. Dengue, urbanization and globalization: the Unholy trinity of the 21(st) Century. Trop Med Health 2011;39:S3-11.

14 Ganeshkumar P, Murhekar MV, Poornima V, et al. Dengue infection in India: a systematic review and meta-analysis. PLoS Negl Trop Dis 2018;12:e0006618.

15 Gubler DJ. The global emergence/resurgence of arboviral diseases as public health problems. Arch Med Res 2002;33:330-42.

16 Bhatt BM, Joshi JP. GIS in epidemiology: applications and services. Nat J Comm Med 2012;3:259-63.

17 Gupta E, Dar L, Kapoor G, et al. The changing epidemiology of dengue in Delhi, India. Virol J 2006;3:92.

18 Telle O, Vaguet A, Yadav NK, et al. The spread of dengue in an endemic urban milieu-the case of Delhi, India. PLoS One 2016;11:e0146539.

19 Chang K. Introduction to geographic information systems. New York, 2010: 327-40.

20 Ord JK, Getis A. Local spatial autocorrelation statistics: distributional issues and an application. Geogr Anal 1995;27:286-306.

21 Hinman SE, Blackburn JK, Curtis A. Spatial and temporal structure of typhoid outbreaks in Washington, D.C., 1906-1909: evaluating local clustering with the Gi* statistic. Int J Health Geogr 2006;5:13.

22 Getis A, Morrison AC, Gray K, et al. Characteristics of the spatial pattern of the dengue vector, Aedes aegypti, in lquitos, Peru. Am J Trop Med Hyg 2003;69:494-505.

23 Agarwal R, Kapoor S, Nagar R, et al. A clinical study of the patients with dengue hemorrhagic fever during the epidemic of 1996 at Lucknow, India. Southeast Asian J Trop Med Public Health 1999;30:735-40.

24 Ray G, Kumar V, Kapoor AK, et al. Status of antioxidants and other biochemical abnormalities in children with dengue fever. J Trop Pediatr 1999;45:4-7.

25 Wali JP, Biswas A, Handa R, et al. Dengue haemorrhagic fever in adults: a prospective study of 110 cases. Trop Doct 1999;29:27-30.

26 Antony J, Celine TM. A descriptive study on dengue fever reported in a medical college hospital. Sahel Med J 2014;17:83-6.

27 El-Gilany A-H, Eldeib A, Hammad S. Clinico-epidemiological features of dengue fever in Saudi Arabia. Asian Pac J Trop Med 2010;3:220-3.

28 Anker M, Arima Y. Male differences in the number of reported incident dengue fever cases in six Asian countries. Western Pac Surveill Response J 2011;2:e1-23.

29 Bhaswati B, Indrani B, Srima A. A comprehensive study on the 2012 dengue fever outbreak in Kolkata, India. ISRN Virology 2013;2013.

30 Jain S, Dixit GT, Kohli V. Trend and epidemiological profile of dengue Fever/Dengue haemorrhagic fever in Ahmedabad City, Gujarat, India. Healthline J 2019;10.

31 Rigau-Pérez JG, Clark GG, Gubler DJ, et al. Dengue and dengue haemorrhagic fever. Lancet 1998;352:971-7.

32 Ramachandran VG, Roy P, Das S, et al. Empirical model for estimating dengue incidence using temperature, rainfall, and relative humidity: a 19-year retrospective analysis in East Delhi. Epidemiol Health 2016;38:e2016052.

33 Morin CW, Comrie AC, Ernst K. Climate and dengue transmission: evidence and implications. Environ Health Perspect 2013;121:1264-72.

34 Joshua V, Kaliaperumal K, Krishnamurthy KB, et al. Exploration of population ecological factors related to the spatial heterogeneity of dengue fever cases diagnosed through a national network of laboratories in India, 2017. Indian J Med Res 2020;151:79-86.

35 Vincenti-Gonzalez MF, Grillet M-E, Velasco-Salas Zl, et al. Spatial analysis of dengue seroprevalence and modeling of transmission risk factors in a dengue hyperendemic city of Venezuela. PLoS Negl Trop Dis 2017;11:e0005317. 